\title{
Infeção Cutânea por Citomegalovírus em Doente com Infecção VIH/SIDA
}

\author{
Marcelo Jaime Banquimane', Eliane Carmo dos Santos Monteiro Samo Gudo², Amélia Conceição da Cunha ${ }^{3}$ Rolanda Carmen \\ Manuel ${ }^{3}$, Maria Goreti Catorze 4 , Maria del Pillar Montero3, Gilda da Graça M. Luciano ${ }^{3}$ \\ 'Médico Interno de Dermatologia e Venereologia/Resident, Dermatology and Venereology; Hospital Central de Maputo, \\ Moçambique \\ ${ }^{2}$ Médica Especialista em Patologia/Specialist, Pathology; Hospital Central de Maputo, Moçambique \\ ${ }^{3}$ Médica Especialista em Dermatologia e Venereologia/Specialist, Dermatology and Venereology; Hospital Central de Maputo, \\ Moçambique \\ ${ }^{4}$ Médica Especialista em Dermatologia e Venereologia/Specialist, Dermatology and Venereology; Centro Hospitalar de Lisboa \\ Ocidental, Hospital de Egas Moniz, Lisboa, Portugal
}

RESUMO - A infecção por citomegalovírus tem distribuição mundial com alta prevalência nos países subdesenvolvidos, onde atinge quase $100 \%$ da população. As manifestações cutâneas são raras. A apresentação inespecífica das mesmas pode contribuir para o subdiagnóstico da doença. Relatamos o caso clínico de uma doente de 24 anos, gravemente imunodeprimida, com ulcerações na pele com quatro meses de evolução, e diagnóstico de infecção por vírus de imunodeficiência humana tipo 1 dois meses após o início das lesões. Na terceira semana de internamento desenvolveu uma retinite aguda por citomegalovírus e, embora tenha iniciado tratamento antirretrovírico e depois ganciclovir acabou por falecer após três meses por pericardite aguda.

PALAVRAS-CHAVE - Dermatopatias Virais; Infecções por Citomegalovirus; Infecções por VIH; Infecções Oportunistas Relacionadas com a SIDA; Moçambique.

\section{Cutaneous infection with cytomegalovirus in patients with HIV / AIDS infection}

ABSTRACT - Infection by cytomegalovirus has worldwide distribution with high prevalence in developing countries, where it reaches almost $100 \%$ of the population. Cutaneous manifestations are rare. Moreover, unspecific presentation of dermatological lesions may contribute to subdiagnosis of the disease. We report a case of a 24 years-old female patient, severely immunocompromised, with ulcerations on the skin with 4 months of evolution, diagnosed with human immunodeficiency virus type 1 infection two months after the onset of lesions. In the third week of hospitalization she developed an acute cytomegalovirus retinitis, and despite initiation of anti-retroviral and anti-cytomegalovirus treatment initiation, she died after three months with an acute pericarditis.

KEY-WORDS - AIDS-Related Opportunistic Infections; Cytomegalovirus Infections; HIV Infections; Mozambique; Skin Diseases, Viral.

\section{INTRODUÇÃO}

O citomegalovírus (CMV) é um vírus pertencente à família Herpesviradae, cuja patogénese, à semelhança de outros herpesvírus, obedece à sequência primo-infeção, latência e reactivação. ' A prevalência da infecção pelo $\mathrm{CMV}$ é variável: cerca de $40 \%$ nos países desenvolvidos e quase $100 \%$ nos subdesenvolvidos. ${ }^{2}$ Pensa-se que a elevada prevalência nestes últimos países se deva, entre outros fatores, a más condições de higiene relacionados com grandes aglomerados populacionais onde coabitam, em pequenos espaços, numerosos adultos e crianças. ${ }^{1}$

A principal forma de transmissão do CMV é o contacto sexual embora, para além do esperma e secreções cervicovaginais, sejam também veículos de transmissão do vírus a
Correspondência: Marcelo Jaime Banquimane

Serviço de Dermatologia - Departamento de Medicina Interna

Hospital Central de Maputo - Maputo Cidade, Moçambique

E-mail: banquimane@hotmail.com
Recebido/Received

17 Agosto/17 August 2016

Aceite/Accepted

10 Outubro/10 October 2016 


\section{Caso Clínico}

urina, saliva, leite materno e sangue. , $^{1,3}$ Nas transfusões sanguíneas o risco de transmissão é de $3-4 \%$ por cada unidade de sangue transfundido.

Mais de $90 \%$ dos indivíduos imunocompetentes com infeção por CMV são assintomáticos. ' Quando sintomática, a primo-infeção por CMV apresenta-se sob a forma de síndrome mononucleose-like.' Já nos doentes imunodeprimidos, as manifestações clínicas ocorrem por reativação do $\mathrm{CMV}$, sendo as oftalmológicas as mais frequentes. As manifestações cutâneas são raras e, quando presentes, têm um polimorfismo lesional caracterizado por vesículas, nódulos, placas verrucosas ou ulcerações orais, perianais e genitais. ${ }^{1,3,4}$

O tratamento e a profilaxia da infeção por CMV em imunodeprimidos incluem ganciclovir (iv), valganciclovir (po), foscarnet (iv) ou cidofovir (iv). ${ }^{1,5,6}$

Apresentamos o caso de uma doente com síndrome de imunodeficiência adquirida (SIDA), gravemente imunodeprimida, com ulcerações extensas provocadas por CMV.

\section{RELATO DO CASO}

Descreve-se o caso clínico de uma doente de 24 anos de idade, natural e residente em Maputo (Moçambique), doméstica, internada no serviço de Dermatologia do Hospital Central de Maputo por nódulos e placas ulceradas e dolorosas da pele, com 4 meses de evolução; foi detectada seropositividade para o vírus de imunodeficiência humana tipo 1 (VIH-1) 2 meses antes do internamento. Sem dados relevantes na história pessoal, familiar e ginecológica.

O exame da pele revelou lesões dispersas na face, membros e região glútea. Na hemiface esquerda observavam-se nódulos ulcerados de bordos regulares e elevados, fundo limpo, eritematoso e com sangramento espontâneo (Fig. 1). Nos membros superiores e inferiores observavam-se placas arredondadas, ulceradas, de tamanhos variando entre 6 a $10 \mathrm{~cm}$ de diâmetro, distribuição assimétrica, bordos regulares e elevados e fundo eritematoso com ligeiro exsudado esbranquiçado. Sem lesões na conjuntiva, mucosa oral ou genital.

As análises laboratoriais revelaram anemia de $8,5 \mathrm{gr} /$ $\mathrm{dL}$, linfopénia de $0,4 \times 10^{3} / \mathrm{ul}(10 \%)$ e contagem de linfócitos TCD4+ de 1 célula/ul (0\%). A ecografia abdominal não se revelou alterada. A cultura do exsudado superficial da placa ulcerada do ombro esquerdo resultou no isolamento de Staphylococus aureus tendo sido tratada com ciprofloxacina 500mg, 2 vezes por dia, durante 7 dias. O RPR (rapid plasma reagin) foi negativo. A pesquisa de CMV por PCR (polymerase chain reaction) e as cargas virais do $\mathrm{VIH}-1$ e CMV não foram feitas por falta de recursos técnicos para a sua realização.

Foi realizada biópsia cutânea da lesão do ombro esquerdo cujo exame histopatológico mostrou área com ulceração,

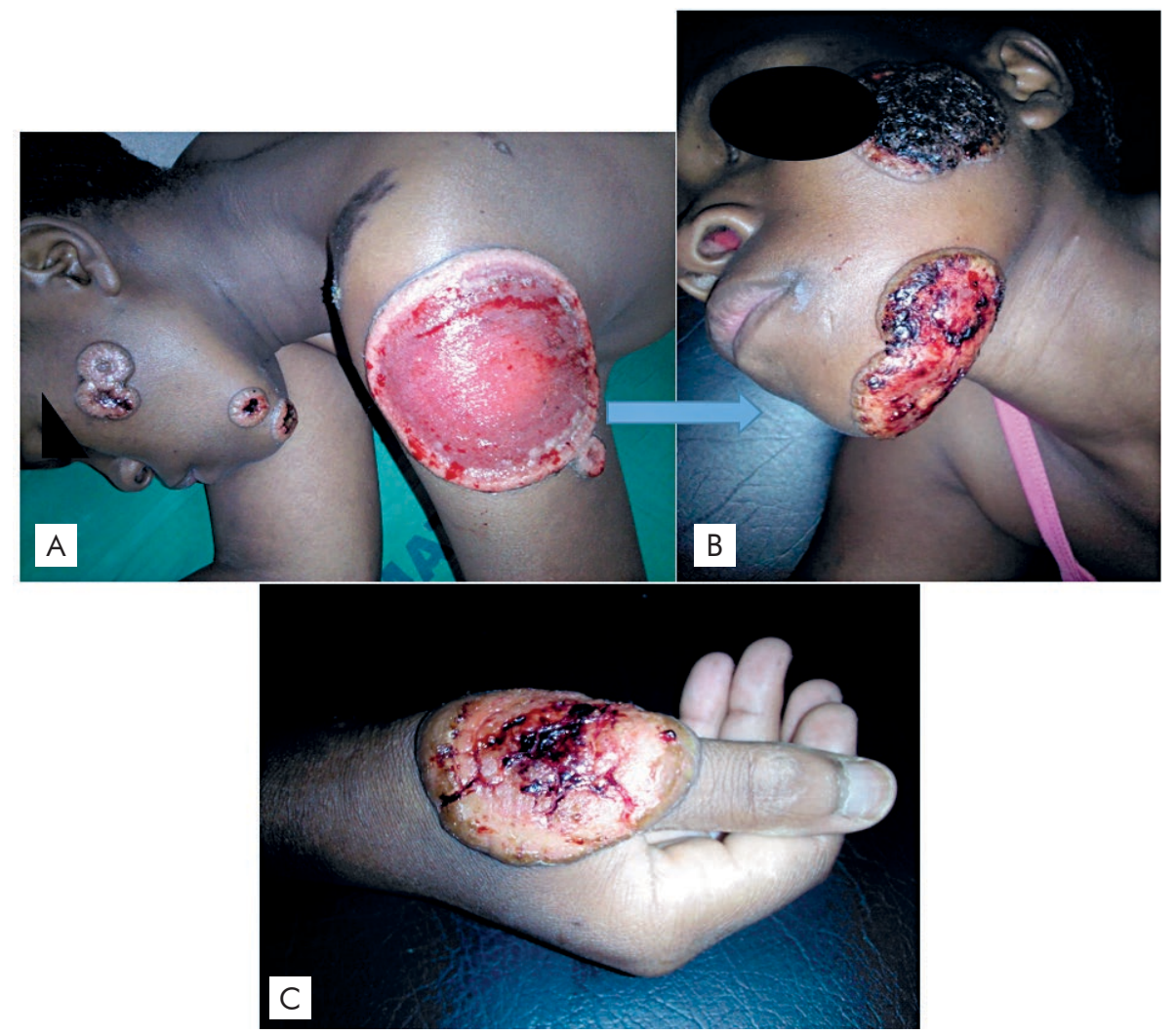

Figura 1 - (A) Lesões no dia de internamento; (B) Após 2 meses de internamento. Aumento de tamanho das lesões; (C) Placa ulcerada na mão direita. 


\section{Caso Clínico}
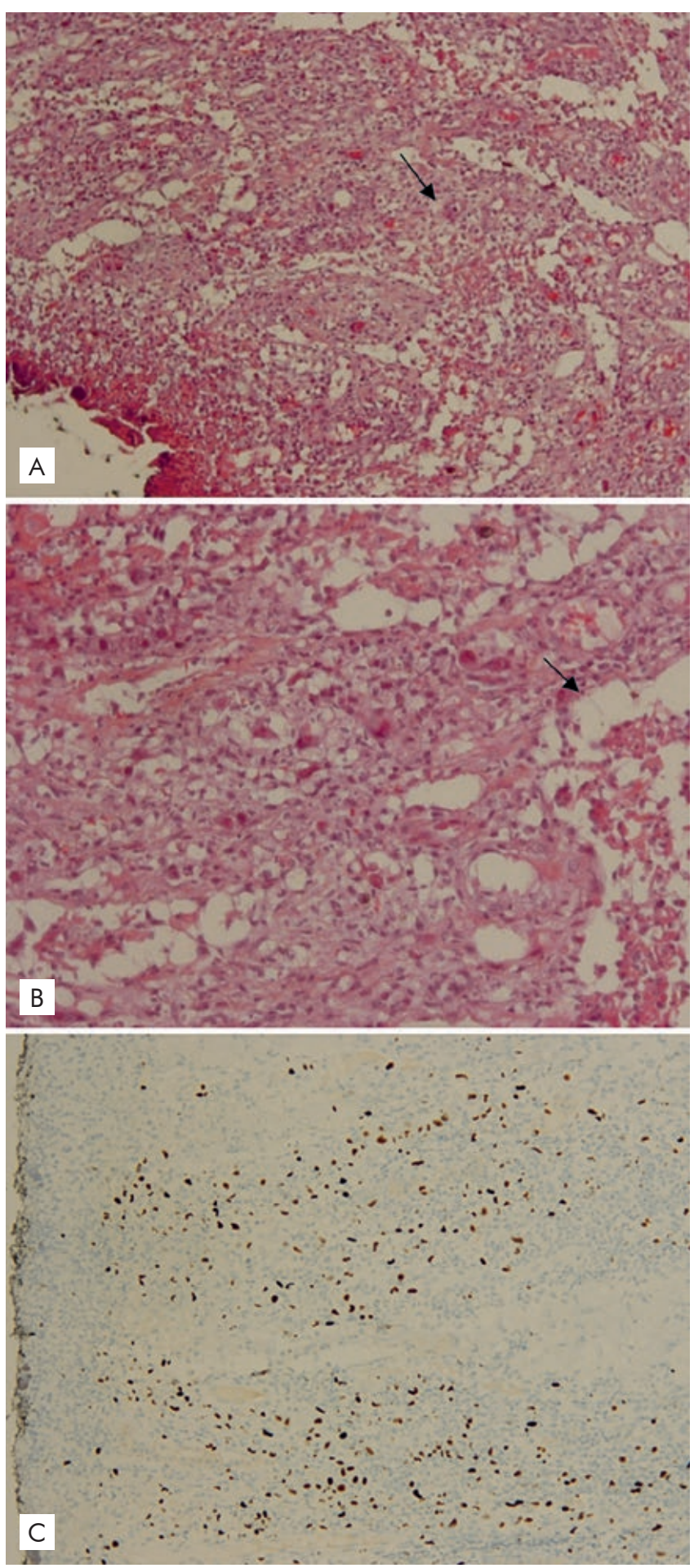

Figura 2 - Estudo histopatológico de biopsia do ombro (A,B - Na coloração pela hematoxilina e eosina, observam-se corpos de inclusão basofílicos intranucleares (setas) e tumefação das células endoteliais; C - Estudo imunohistoquímica com anticorpo anti-CMV).

acantose da epiderme à periferia, espongiose e células epiteliais pavimentosas grandes dispersas com efeito citopático, com corpos de inclusão grandes, basofílicos intranucleares, além de infiltrado inflamatório mononuclear com alguns leucócitos polimorfonucleares, neutrófilos e eosinófilos na epiderme. $\mathrm{Na}$ derme observava-se escasso infiltrado linfocitário (Fig. 2); havia ectasia vascular com tumefação de células endoteliais e presença de inclusões intranucleares que por exame imunohistoquímico com anticorpos contra antigénios de CMV confirmaram a presença deste vírus.

Às duas semanas de internamento, iniciou tratamento antirretrovírico combinado (TARC) com tenofovir, lamivudina e efavirenz (TDF+3TC+EFV). Na terceira semana de internamento, a doente desenvolveu visão turva tendo sido avaliada pela Oftamologia. A fundoscopia demonstrou alterações sugestivas de retinite por CMV à direita, nomeadamente exsudado algodonoso e hemorragia em chama de vela na arcada temporal superior, sem alterações da papila ou da mácula.

Após a confirmação imunohistoquímica de CMV na biópsia cutânea (4 semanas de internamento), iniciou ganciclovir endovenoso 250mg de 12 em 12 horas $(5 \mathrm{mg} / \mathrm{kg}$ ).

Dois meses e meio após o início de TARC e aos 2 meses de tratamento com ganciclovir, ocorreu agravamento do estado geral e a doente veio a falecer por pericardite aguda, de etiologia não esclarecida.

\section{DISCUSSÃO}

Embora rara, a infeção cutânea por CMV tem elevadas taxas de morbilidade e mortalidade, particularmente em indivíduos com infeção VIH-1 não controlada, em estádio de SIDA. 1,3 Em Moçambique, segundo dados de 2015, a prevalência do VIH é de $11 \%$, sendo infetadas diariamente 320 pessoas. $^{7}$

A taxa da infeção por CMV em indivíduos com VIH é muito elevada. Na Nigéria, segundo Fowotade et al, ${ }^{8}$ é de 93,9 \%. Em Moçambique, não existem dados estatísticos oficiais sobre a prevalência da infeção CMV em doentes com VIH. Apesar da alta prevalência, apenas 40\% destes apresentam manifestações clínicas. ${ }^{9}$ A retinite por $\mathrm{CMV}$ é a manifestação mais frequente. $O$ envolvimento cutâneo é raro. Quando presente, manifesta-se por lesões polimorfas e inespecíficas caracterizadas por vesículas, nódulos, placas verrucosas e úlceras, com localização habitualmente perianal, genital e oral. ${ }^{1,10}$

No caso aqui descrito, as áreas afetadas foram face, membros e tronco, o que nos alerta para manifestações e localizações atípicas desta infeção e necessidade de melhor compreensão da patogénese da infeção cutânea por CMV.

O diagnóstico "padrão" da infeção por CMV é a cultura do vírus em fibroblastos humanos. ${ }^{1} \mathrm{O}$ inconveniente deste método é a demora em obter o resultado. ${ }^{1}$ Hoje em dia, técnicas de amplificação de $A D N$ mediante $P C R$ têm sido usadas com regularidade. ${ }^{11} \mathrm{Na}$ doença cutânea, a histologia tem um valor diagnóstico importante: células em "olho de corvja" que correspondem ao aumento do citoplasma, presença de corpos de inclusão intranuclear cristalino a roxo rodeado de um halo claro são características histopatológicas desta infeção. 


\section{Caso Clínico}

A doença citomegálica disseminada ou visceral (a exceção do envolvimento hepático, ganglionar e esplénico das formas agudas) é definidor de SIDA no doente com infeção $\mathrm{VIH}-1 .{ }^{12,13}$ Esta infeção oportunista ocorre com maior probabilidade em doentes com TCD4 + <200 células/ul, embora possa ocorrer acima deste valor. Para Kovacs et als, isto é demonstrável quando se estudam recém-nascidos mas não está claro para os adultos. ${ }^{12}$ Para Spector et al, a carga viral do CMV é um fator preditivo para o surgimento de manifestações clínicas do CMV independentemente da carga viral do $\mathrm{VIH}$ em indivíduos com SIDA. ${ }^{14,15} \mathrm{O}$ mecanismo pelo qual isso ocorre ainda é incerto, mas pensa-se que a ampla imunodesrregulação associada á disfunção de linfócitos TCD4+ e TCD8+, subjacente a infeção crónica e prolongada por $\mathrm{VIH}$, possa favorecer a replicação do citomegalovírus. ${ }^{12,14}$ Por outro lado, é controverso o papel patogénico do CMV nas lesões cutâneas: alguns autores especulam que outros agentes co-infectantes (vírus herpes simplex, vírus varicela-zoster), possam ter um papel etiológico sendo que o $\mathrm{CMV}$ mantém a cronicidade das lesões. ${ }^{16} \mathrm{~A}$ favor desta teoria são: 1) a presença do vírus em áreas de pele íntegra e, 2) a associação frequente do CMV com outros microrganismos como vírus herpes simplex e varicela-zoster.

A infeção cutânea por CMV, particularmente nos casos associados a doença disseminada, faz prever prognóstico desfavorável. ${ }^{17}$ Vários fatores permitem justificar o mau prognóstico destes doentes, em geral, e deste caso, em particular. $\mathrm{O}$ estadio avançado da infeção por VIH-1 (C3, segundo a classificação do CDC de Atlanta), com imunodepressão muito grave, sugere a possibilidade de uma infeção por CMV disseminada, com provável envolvimento de múltiplos órgãos de forma latente e que se exacerbou do ponto de vista clínico após início da TARC muito provavelmente por um fenómeno de reconstituição imunológica ainda que não estejam disponíveis os valores de TCD4 + seguintes e da carga viral do $\mathrm{VIH}$ por falta de recursos técnicos. Tal pode justificar a retinite por CMV cerca de uma semana após início da TARC. Não se pode também excluir a probabilidade elevada de outras infeções oportunistas neste contexto de extrema imunodepressão que se poderão ter manifestado após a TARC e que poderão estar na origem da pericardite (ex: pericardite tuberculosa entre outras causas menos comuns).

Trazemos este caso para alertar acerca das manifestações dermatológicas exuberantes e atípicas da infeção CMV no doente com infecção VIH em estadio SIDA, devendo incluir-se este agente no diagnóstico diferencial de lesões cutâneas semelhantes, mesmo na ausência de outras manifestações sistémicas/viscerais mais comuns.

\section{Agradecimentos}

Especial agradecimento vai à Dra. Isabel Faro Viana, directora do serviço de Dermatologia do Hospital de Egas Moniz e ao Dr. João Alves, interno de infecciologia no Hospital de Egas Moniz, pelo apoio imensurável que deram para este artigo.
Conflitos de interesse: Os autores declaram não possuir conflitos de interesse. Suporte financeiro: $O$ presente trabalho não foi suportado por nenhum subsídio ou bolsa. Protecção de pessoas e animais: Os autores declaram que os procedimentos seguidos estavam de acordo com os regulamentos estabelecidos pelos responsáveis da Comissão de Investigação Clínica e Ética e de acordo com a Declaração de Helsínquia da Associação Médica Mundial.

Conflicts of interest: The authors have no conflicts of interest to declare. Financing Support: This work has not received any contribution, grant or scholarship. Protection of human and animal subjects: The authors declare that the procedures followed were in accordance with the regulations of the relevant clinical research ethics committee and with those of the Code of Ethics of the World Medical Association (Declaration of Helsinki).

\section{REFERÊNCIAS}

1. Mendoza N, Madkan V, Sra K, Willison B, Morrison KL, Tyring SK. Human herpesviruses. $3^{\text {th }}$ ed. In: Bolognia JL, Jorizzo JL, Schaffer JV, editors. Dermatology. Amsterdam: Elsevier; 2012.p. 1336-8.

2. Krech U.Complement-fixing antibodies against cytomegalovirus in different parts of the world. Bull World Health Organ. 1973; 49:103-6.

3. Franca I, Poiares-Baptista A, Pais MJ, Araújo C, Chorão $M$, MansinhoK, et al. Infecção cutânea por vírus citomegálico em doentes com SIDA Acta Méd Port. 1997; 10:479-84.

4. Choi YL, Kim JA, Jang KT, Kim DS, Kim WS, Lee JH, et al. Characteristics of cutaneous cytomegalovirus infection in non-acquired immune deficiency syndrome, immunocompromised patients. Br J Dermatol. 2006; 155:97782.

5. Lalonde RG, Boivin G, Deschênes J, Hodge WG, Hopkins JJ, Klein, et al. Canadian consensus guidelines for the management of cytomegalovirus disease in HIV/AIDS. Can J Infect Dis Med Microbiol. 2004; 15:327-35.

6. Whitley RJ, Jacobson MA, Friedberg DN, Holland GN, Jabs DA, Dieterich DT, et al. Guidelines for the treatment of Cytomegalovirus diseases in patients with AIDS in the era of potent antiretroviral therapy. Arch Intern Med. 1998; 158:957-69.

7. Matias L. Infeções por HIV/SIDA diminuem em Moçambique [Lusa]. DW.com 2015; [consultado 2016 Maio 4]; Disponível em http://dw.com/p/1FzxM.

8. Fowotade A, Okonko IO, Agbede OO, Suleiman ST. High seropositivity of $\lg G$ and $\lg M$ antibodies against cytomegalovirus (CMV) among HIV-1 seropositive patients in Ilorin, Nigeria. Afr Health Sci. 2015; 15:1-9.

9. Kirubakaran I, Cytomegalovirus infection in HIV-Infected Patients - A Review. JHAS. 2004; 26:18.

10. Cachafeiro TH, Escobar GF, Bakos L, Bakos RM. Chronic cutaneous cytomegalovirus infection in a patient with severe combined immunodeficiency syndrome. $\mathrm{Br} \mathrm{J}$ 


\section{Caso Clínico}

Dermatol. 2014; 170:223-5.

11. Kovacs A, Schluchter M, Easley K, Demmler G, Shearer W, La Russa P, et al. Cytomegalovirus infection and HIV-1 disease progression in infants born to HIV-1-infected women. Pediatric Pulmonary and Cardiovascular Complications of Vertically Transmitted HIV Infection Study Group. N Engl J Med. 1999; 341:77-84.

12. Daudén $E$, Fernández-Buezo G, Fraga J, Cardeñoso L, García-Díez A. Mucocutaneous presence of cytomegalovirus associated with human immunodeficiency virus infection: discussion regarding its pathogenetic role. Arch Dermatol. 2001; 137:443-8.

13. Caliendo AM. Overview of diagnostic tests for cytomegalovirus infection [literature review] uptodate.com; 2015[consultado 2016 Abril 23]; Disponível em: http:// www.uptodate.com.

14. Spector SA, Hsia K, Crager M, Pilcher M, Cabral S, Stempien MJ. Cytomegalovirus (CMV) DNA load is an independent predictor of $\mathrm{CMV}$ disease and survival in advanced AIDS. J Virol. 1999; 73:7027-30.

15. Deayton JR, Sabin CA, Britt WB, Jones IM, Wilson P, Johnson $M A$, et al. Rapid reconstitution of humoral immunity against cytomegalovirus but not HIV following highly active antiretroviral therapy. AIDS. 2002; 16:2129-35.

16. Lázaro $M$, Rodrigues I. Co-infecção $\mathrm{CMV} / \mathrm{VIH}$ uma associação mortal. [consultado 2016/05/14 3],Disponível em: http://www.hdl.handle.net.

17. Lee JY. Cytomegalovirus infection involving the skin in immunocompromised hosts. A clinicopathologic study. Am J Clin Pathol. 1989; 92:96-100. 